\title{
SCALAR APPROXIMANTS OF QUADRATIC OPERATORS WITH APPLICATIONS
}

\author{
AMER ABU-OMAR AND PEI YUAN Wu
}

Abstract. Among other results, we find the best scalar approximant of a quadratic operator with respect to the numerical radius and the operator norm. We use these results to give estimates for the numerical radii of products and commutators of quadratic operators.

Mathematics subject classification (2010): Primary 47A12, Secondary 47A30, 47A63. Keywords and phrases: Numerical range, quadratic operator, scalar approximant.

\section{REFERENCES}

[1] A. ABU-OMAR And F. KitTAneh, Upper and lower bounds for the numerical radius with an application to involution operators, Rocky Mountain J. Math. 45 (2015), 1055-1065.

[2] A. ABU-OMAR AND F. KitTANeH, Notes on some spectral radius and numerical radius inequalities, Studia Math. 227 (2015), 97-109.

[3] A. ABU-Omar And F. Kittaneh, Numerical radius inequalities for products and commutators of operators, Houston J. Math. 41 (2015), 1163-1173.

[4] A. ABU-OMAR AND F. KitTANeH, Numerical radius inequalities for products of Hilbert space operators, J. Operator Theory 72 (2014), 101-107.

[5] K. M. R. AUDENAERT, Variance bounds, with an application to norm bounds for commutators, Linear Algebra Appl. 432 (2010), 1126-1143.

[6] C. K. Fong And J. A. Holbrook, Unitarily invariant operator norms, Canad. J. Math. 35 (1983), 274-299.

[7] H.-L. GAU, C.-Y. HUANG AND P. Y. WU, Numerical radius inequalities for square-zero and idempotent operators, Oper. Matrices 2 (2008), 137-141.

[8] K. E. Gustafson And D. K. M. RaO, Numerical Range, Springer, New York, 1997.

[9] P. R. Halmos, Matrices Near Matrices, unpublished notes, 1991.

[10] P. R. Halmos, A Hilbert Space Problem Book, 2nd ed., Springer, New York, 1982.

[11] J. C. Hou AND H. K. DU, Norm inequalities of positive operator matrices, Integral Equations Operator Theory 22 (1995), 281-294.

[12] C. R. Johnson, I. M. Spitkovsky AND S. GotTLIEB, Inequalities involving the numerical radius, Linear Multilinear Algebra 37 (1994), 13-24.

[13] F. Kittaneh, Commutator inequalities associated with the polar decomposition, Proc. Amer. Math. Soc. 130 (2002), 1279-1283.

[14] V. MüLLER, The numerical radius of a commuting product, Michigan Math. J. 35 (1988), 255-260.

[15] D. K. M. RAO, Rango numerico de operadores commutativos, Rev. Colombiana Mat. 27 (1994), 231-233.

[16] J. G. Stampfli, The norm of a derivation, Pacific J. Math. 33 (1970), 737-747.

[17] S.-H. Tso AND P. Y. WU, Matricial ranges of quadratic operators, Rocky Mountain J. Math. 29 (1999), 1139-1152.

[18] P. Y. Wu, H.-L. GaU And M. C. TsaI, Numerical radius inequality for $C_{0}$ contractions, Linear Algebra Appl. 430 (2009), 1509-1516. 